\title{
INDEX OF ORTHODONTIC TREATMENT NEED IN A REFERRED NEPALESE POPULATION
}

\author{
Dr. Sujita Shrestha, ${ }^{1}$ Dr. Rabindra Man Shrestha ${ }^{2}$ \\ 1. Lecturer, Dept of Community \& Public Health Dentistry, Kantipur Dental College, Kathmandu \\ 2. Associate Professor, Dept of Orthodontics, Kantipur Dental College, Kathmandu \\ Correspondence : shresthasujita@hotmail.com
}

\section{ABSTRACT}

Objective: The study aims to assess the need for orthodontic treatment in a group of referred Nepalese population of Kathmandu valley.

Materials and method: Dental Health Component (DHC) and Aesthetic Component (AC) of the Index of Orthodontic Treatment Need (IOTN) was evaluated on a group of 412 Nepalese orthodontic patients including 142 male and 270 female subjects aged $11-30$ years with the mean age 17.12 years by a single examiner.

Result: Dental Health Component showed $16 \%$ no/little treatment need, $19.9 \%$ showed borderline need, and $64.1 \%$ showed great/severe treatment need. Aesthetic Component showed $26.5 \%$ no/little treatment need, $32 \%$ showed borderline need, and $41.5 \%$ showed great/severe treatment need.

Conclusion: Increasing trend of treatment need for more severe forms of orthodontic problems seen in Nepalese orthodontic patients according to DHC and AC scores in age groups 11-25 years and for both male and female gender groups.

Key words: index, malocclusion, orthodontic treatment, referred population

\section{INTRODUCTION:}

Over the past decades, the impact of oral health, oral disease, malocclusion, dental appearance, facial aesthetics, and their management on psychological and functional well-being has drawn increasing attention for clinicians and researchers. The oral-facial region is usually an area of significant concern for the individual because it draws the attention from other people in interpersonal interactions and is the primary source of vocal, physical, and emotional communication. Facial and dental attractiveness represents an important element on quality of life. An attractive smile and well-aligned teeth are important to laypersons, perhaps more valued than the improved oral function. According to some studies in social-psychology, it has been shown that physical appearance of an individual play an important role in his/ her social relations and facilitate in obtaining social skills. ${ }^{1}$ Thus it is necessary to determine the patient who is in need of orthodontic treatment and prioritize those with higher treatment needs.

Malocclusion is a public health concern in population; however due lack of orthodontic awareness on treatment need and lack of availability of population data; epidemiological study is required for evaluation and planning of orthodontic services. Several indices have been developed to categorize malocclusion into groups according to the level of treatment need. Some of the examples are Grainger's Treatment Priority Index (1967), ${ }^{2}$ Salzmann's Handicapping Malocclusion Assessment Record (1968), ${ }^{3}$ Summer's Occlusal Index (1971). ${ }^{4}$ In recent years; the Index of Orthodontic Treatment Need $(\text { IOTN })^{5}$ and the Peer Assessment Rating (PAR) 6 are being used more commonly to assess orthodontic treatment need, priority, and evaluation of treatment success.

Index of Orthodontic Treatment Need (IOTN) was first developed in Britain by Brook and Shaw in1989 as a system for grading malocclusions. ${ }^{5}$ The aesthetic component of IOTN was developed originally by Evan \& Shaw in $1987 .{ }^{7}$ The British Orthodontic Society states that; if the treatment has to be rationalized the IOTN is an objective and reliable way for specialists to select the patients who will benefit most from the treatment and is a fair way to prioritize the limited health service resources.

Various studies on determination of orthodontic treatment needs were carried out on the basis of IOTN by different authors: Brook and Shaw (1989), ${ }^{5}$ Burden and Holmes (1994), ${ }^{8}$ Mandall et al. (1999), ${ }^{9}$ Kok et al. (2004), ${ }^{10}$ Holmes and Willmot (1996); ${ }^{11}$ and in different countries: England (Brook \& Shaw 1989, Richmond et al 1994), 5, 12, ${ }^{13}$ Norway (Birkeland et al., 2000), ${ }^{1}$ Switzerland (Firestone et al, 1999), ${ }^{14}$ Turkey (Ucuncu and Ertugay, 2001), ${ }^{15}$ Iran (Hedayati et al. 2007, Padisar et al 2009) ${ }^{16,17}$ and Pakistan (Zahid et al. 2012). ${ }^{18}$ Thus the study aims to assess the need for orthodontic treatment in a group of referred Nepalese population of Kathmandu valley.

\section{MATERIALS AND METHOD:}

A study on Index of Orthodontic Treatment Need (IOTN) was done to assess the orthodontic treatment need in a referred Nepalese population. A total of 412 patients with 


\section{ORTHODONTIC JOURNAL OF NEPAL}

142 male and 270 female of the age ranging from 11-30 were included in the study. The study was conducted among the patients of Department of Orthodontics, Kantipur Dental College Teaching Hospital \& Research Center (KDCH), Kathmandu who were seeking orthodontic treatment during the year 2008-2012. The subjects were evaluated using dental cast and intra-oral photograph.

IOTN comprise of two components: Dental Health Component (DHC) and Aesthetic Component (AC). The accurate use of IOTN requires specialist training. The objective assessment of Dental Health Component and the subjective assessment of Aesthetic Component should take place in a specialist practice. Thus the qualified specialist orthodontist; co-author of the present research evaluated the samples used in the study. To maintain reproducibility and reliability of the data, all the data were collected and measured by a single examiner. The study was conducted as per the guidelines published by the European Orthodontic Society. The subjects were also assessed for the distribution of malocclusion status according to Angle's classification based on molar relation. Data were analyzed using SPSS 16.0 version.

\section{DENTAL HEALTH COMPONENT (DHC):}

Dental Health Component can be examined either clinically or on the study model. In the present study, dental stone study model were used to determine the DHC. Study models were examined and graded by the specialist to determine the DHC of the IOTN. The grades of DHC are based on occlusal characteristics: overjet, overbite, crossbite, contact point displacement, missing teeth and other occlusal abnormalities.

Dental Health Component (DHC) comprise of 5 grades: Grade 1- no treatment need, Grade 2- slight/ little treatment need, Grade 3- moderate/borderline treatment need, Grade 4- great treatment need, Grade 5- very great treatment need.

\section{Dental Health Component Grades:}

\section{Grade 1: No treatment need}

1 - Extremely minor malocclusions including displacements less than $1 \mathrm{~mm}$

\section{Grade 2: Little treatment need}

2a - Increased overjet greater than $3.5 \mathrm{~mm}$ but less than or equal to $6 \mathrm{~mm}$ with competent lips

$2 \mathrm{~b}$ - Reverse overjet greater than $0 \mathrm{~mm}$ but less than or equal to $1 \mathrm{~mm}$

$2 \mathrm{c}$ - Anterior or posterior crossbite with less than or equal to $1 \mathrm{~mm}$ discrepancy between retruded contact position and intercuspal position

$2 \mathrm{~d}$ - Displacement of teeth greater than $1 \mathrm{~mm}$ but less than or equal to $2 \mathrm{~mm}$

$2 \mathrm{e}$ - Anterior or posterior open bite greater than $1 \mathrm{~mm}$ but less than or equal to $2 \mathrm{~mm}$

$2 \mathrm{f}$ - Increased overbite greater than or equal to $3.5 \mathrm{~mm}$ without gingival contact

$2 \mathrm{~g}$ - Prenormal or postnormal occlusion with no other anomalies. Includes up to half a unit discrepancy

\section{Grade 3: Moderate or Borderline treatment need}

$3 a$ - Increased overjet greater than $3.5 \mathrm{~mm}$ but less than or equal to $6 \mathrm{~mm}$ with incompetent lips

$3 \mathrm{~b}$ - Reverse overjet greater than $1 \mathrm{~mm}$ but less than or equal to $3.5 \mathrm{~mm}$

$3 \mathrm{c}$ - Anterior or posterior crossbite with greater $1 \mathrm{~mm}$ but less than or equal to $2 \mathrm{~mm}$ discrepancy between retruded contact position and intercuspal position

$3 \mathrm{~d}$ - Displacement of teeth greater than $2 \mathrm{~mm}$ but less than or equal to $4 \mathrm{~mm}$

$3 e$ - Lateral or anterior open bite greater than $2 \mathrm{~mm}$ but less than or equal to $4 \mathrm{~mm}$

$3 f$ - Increased and complete overbite without gingival or palatal trauma

\section{Grade 4: Great treatment need}

$4 \mathrm{a}$ - Increased overjet greater than $6 \mathrm{~mm}$ but less than or equal to $9 \mathrm{~mm}$

$4 \mathrm{~b}$ - Reverse overjet greater than $3.5 \mathrm{~mm}$ with no masticatory or speech difficulties

$4 \mathrm{c}$ - Anterior or posterior crossbite with greater than $2 \mathrm{~mm}$ discrepancy between retruded contact position and intercuspal position

$4 \mathrm{~d}$ - Severe displacements of teeth greater than $4 \mathrm{~mm}$

$4 \mathrm{e}$ - Extreme lateral or anterior open bite greater than $4 \mathrm{~mm}$

$4 \mathrm{f}$ - Increased and complete overbite with gingival or palatal trauma

$4 \mathrm{~h}$ - Less extensive hypodontia requiring prerestorative orthodontics or orthodontic space closure to obviate the need for a prosthesis

$4 \mathrm{I}$ - Posterior lingual crossbite with no functional occlusal contact in one or both buccal segments

$4 \mathrm{~m}$ - Reverse overjet greater than $1 \mathrm{~mm}$ but less than $3.5 \mathrm{~mm}$ with recorded masticatory and speech difficulties

$4 \mathrm{t}$ - Partially erupted teeth, tipped and impacted against adjacent teeth

$4 \mathrm{x}$ - Existing supernumerary teeth

\section{Grade 5: Very great treatment need}

$5 \mathrm{a}$ - Increased overjet greater than $9 \mathrm{~mm}$

5 h - Extensive hypodontia with restorative implications (more than 1 tooth missing in any quardrant) requiring prerestorative orthodontics

$5 i$ - Impeded eruption of teeth (except 3rd molars) due to crowding, displacement, presence of supernumerary teeth, retained deciduous teeth and any pathological cause

$5 \mathrm{~m}$ - Reverse overjet greater than $3.5 \mathrm{~mm}$ with reported masticatory and speech difficulties

$5 p$ - Defects of cleft lip and palate

$5 s$ - Submerged deciduous teeth 


\section{AESTHETIC COMPONENT (AC):}

The Aesthetic Component consists of 10-grade standard reference color photographs representing different grades of dental attractiveness. Grade 1 represents the most attractive and Grade 10 the least attractive dentitions. Intraoral frontal view color photographs of referred orthodontic patients were used in order to determine the Aesthetic Component (AC) of the index. The examiner assessed the patient's photograph and compared it with the 10-grade reference photos and gave a score to each patient which was considered as the subjective need of the patient.

\section{Aesthetic Component Reference Photographs:}

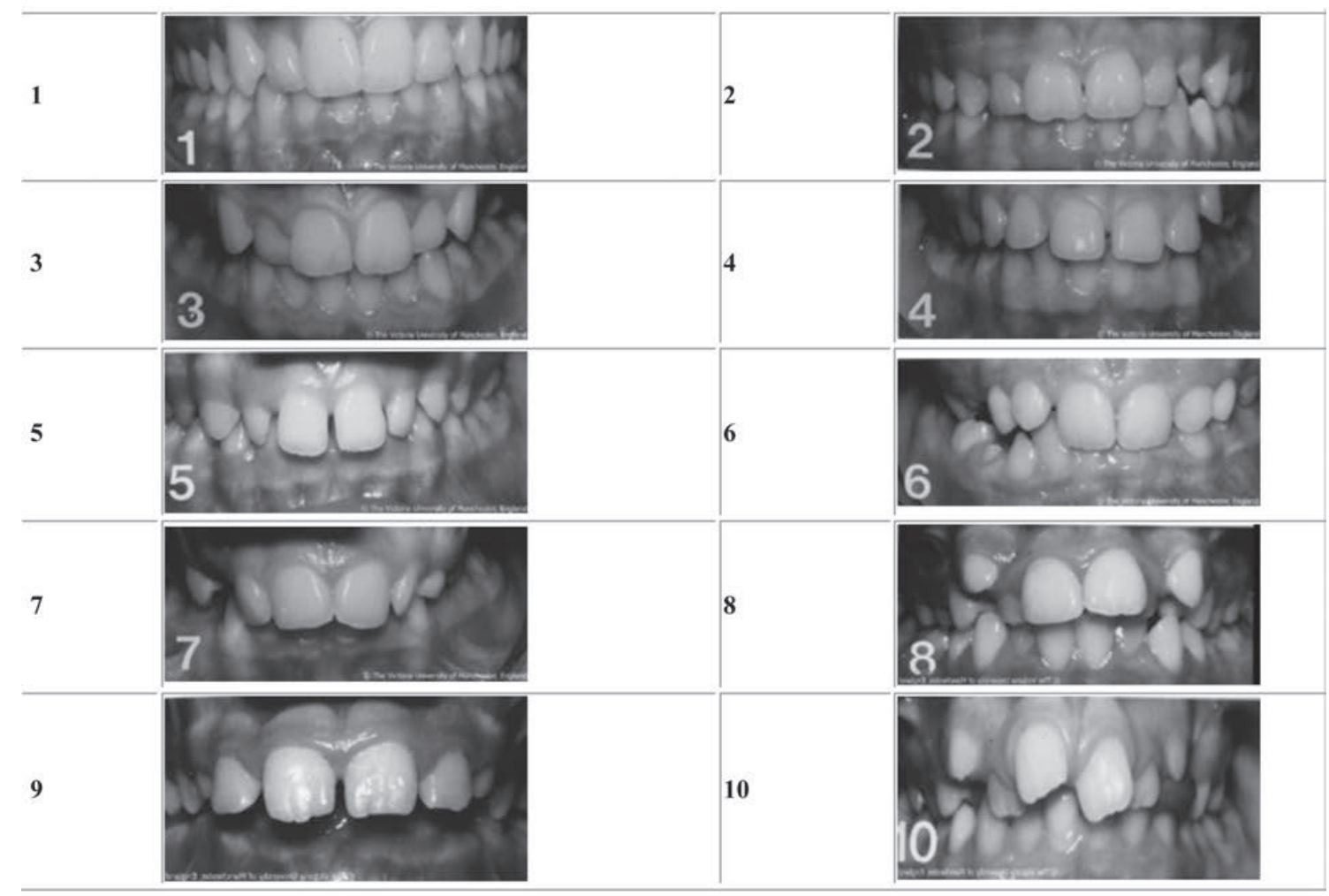

Furthermore, to make the IOTN quicker and easier to use and improve its reliability, the DHC and AC grades were reduced to three scales. This was proposed by Lunn et al in $1993^{19}$ and was accepted and approved by Manchester team which had originally developed IOTN. The DHC Grade 1-2 was scaled as little or no need, Grade 3 was scaled as borderline need and Grade 4-5 was scaled as great or severe need for orthodontic treatment. Similarly, the AC Grade 1-4 was scaled as little or no need, Grade 5-7 was scaled as borderline need and Grade 8-10 was scaled as great or severe need for orthodontic treatment.

\section{RESULT:}

In the present study, 412 orthodontic patients including 142 (34.5\%) male and 270 (65.5\%) female study casts were analyzed. The age of the subjects ranged from 11 to 30 years with mean age 17.12 years. Among 412 patients, 183 (44.4\%) were of age group 11 to 15,151 (36.7\%) were 16 to $20,51(12.3 \%)$ were 21 to 25 and $27(6.6 \%)$ were 26 to 30 years of age (Table 1).

According to Angle's classification; the patients' malocclusion status were 224 (54.4 \%) Class I, 154 (37.3 \%) Class II, and 34 (8.3 \%) Class III (Figure 1).

\section{Table 1: Distribution of subjects according to age and gender}

\begin{tabular}{|c|c|c|c|c|c|}
\hline Age group (in years) & Male & Female & Total & Mean & \\
\hline $11-15$ & 67 & 116 & $183(44.4 \%)$ & 17.12 \\
\hline $16-20$ & 50 & 101 & $151(36.7 \%)$ & \\
\hline $21-25$ & 19 & 32 & $51(12.3 \%)$ & $27(6.6 \%)$ & \\
\hline $26-30$ & 6 & 21 & 412 & \\
\hline Total & 142 & 270 & & \\
\hline
\end{tabular}


Figure 1: Distribution of subjects according to Angle's classification of malocclusion

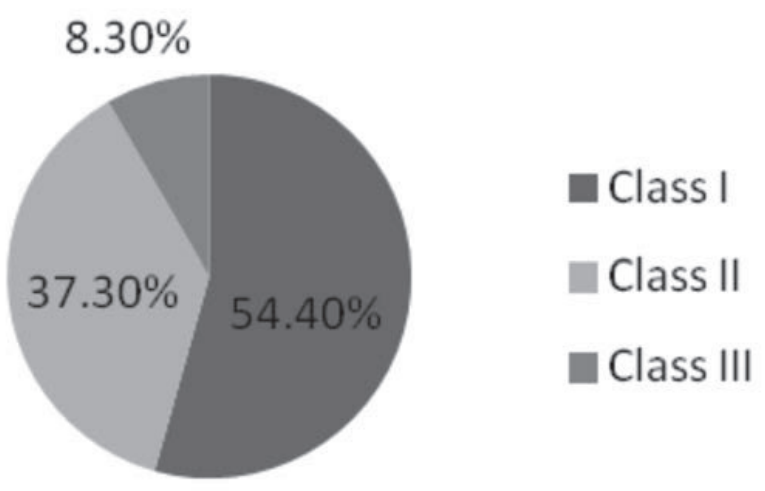

In a total 412 subjects; the Dental Health Component (DHC) showed 11 (2.7\%) Grade 1 (No treatment need), 55 (13.3\%) Grade 2 (Little treatment need), 82 (19.9\%) Grade 3 (Borderline treatment need), 209 (50.7\%) Grade 4 (Great treatment need) and 55 (13.3\%) Grade 5 (Very great treatment need). The distribution of Dental Health Component (DHC) of IOTN is given in Figure 2.

Figure 2: Frequency distribution of Dental Health Component (DHC)

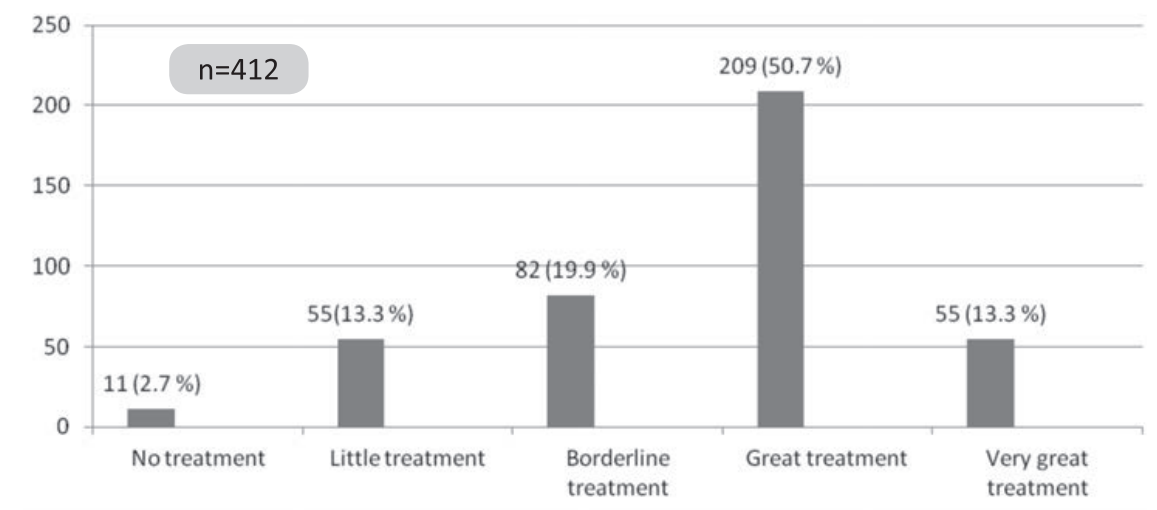

The distribution of grading for the Aesthetic Component (AC) were 8 (1.9\%) AC 1, 26 (6.3 \%) AC 2, 17 (4.1\%) AC 3, 58 (14.1 \%) AC 4, 33 (8 \%) AC 5, 54 (13.1\%) AC 6, 45 (10.9\%) AC 7, 77 (18.7 \%) AC 8, 41 (10 \%) AC 9 and 52 (12.6 \%) AC 10 (Figure 3).

Figure 3: Frequency distribution of Aesthetic Component (AC)

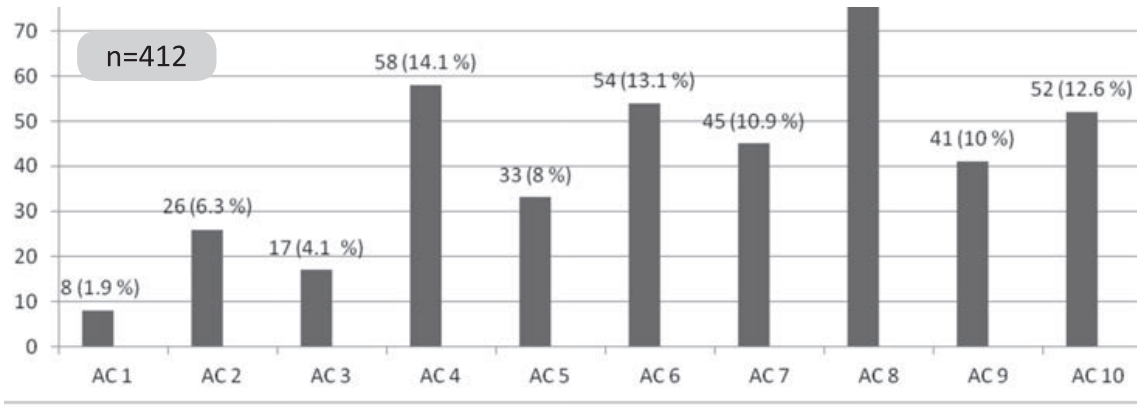

The distribution of Dental Health Component (DHC) scale were 66 (16\%) Grade 1-2 (No/little treatment need), 82 (19.9 \%) Grade 3(Borderline treatment), 264 (64.1\%) Grade 4-5 Great/severe treatment need. The distribution of Aesthetic Component (AC) scale were 109 (26.5 \%) Grade 1-4 No/slight need, 132 (32\%) Grade 5-7 Moderate/borderline need and 171 (41.5 \%) Grade 8-10 Great need. Table 2 and Table 3 represent frequency distribution of DHC scale and AC scale respectively according to the age groups. Table 4 and Table 5 represent frequency distribution of DHC scale and AC scale 
respectively according to gender. Percentage of DHC and AC scale of IOTN is represented in Figure 4.

Table 2: Frequency distribution of DHC scale according to the age groups

\begin{tabular}{|c|c|c|c|c|}
\hline Age group (in years) & No/Little treatment need & Borderline treatment need & Great/Severe treatment need & Total \\
\hline $11-15$ & $23(12.6 \%)$ & $35(19.1 \%)$ & $125(68.3 \%)$ & 183 \\
\hline $16-20$ & $25(16.5 \%)$ & $25(16.5 \%)$ & $101(67 \%)$ & 151 \\
\hline $21-25$ & $10(19.6 \%)$ & $12(23.5 \%)$ & $29(56.9 \%)$ & 51 \\
\hline $26-30$ & $8(29.6 \%)$ & $10(37 \%)$ & $9(33.3 \%)$ & 27 \\
\hline Total & $66(16 \%)$ & $82(19.9 \%)$ & $264(64.1 \%)$ & 412 \\
\hline
\end{tabular}

Table 3: Frequency distribution of AC scale according to the age groups

\begin{tabular}{|c|c|c|c|c|}
\hline Age group (in years) & No/Little treatment need & Borderline treatment need & Great/Severe treatment need & Total \\
\hline $11-15$ & $43(23.5 \%)$ & $57(31.1 \%)$ & $83(45.5 \%)$ & 183 \\
\hline $16-20$ & $39(25.8 \%)$ & $48(31.8 \%)$ & $64(42.4 \%)$ & 151 \\
\hline $21-25$ & $17(33.3 \%)$ & $14(27.5 \%)$ & $20(39.2 \%)$ & 51 \\
\hline $26-30$ & $10(37 \%)$ & $13(48.1 \%)$ & $4(14.9 \%)$ & 27 \\
\hline Total & $109(26.5 \%)$ & $132(32 \%)$ & $171(41.5 \%)$ & 412 \\
\hline
\end{tabular}

Table 4: Frequency distribution of DHC scale according to gender

\begin{tabular}{|l|c|c|c|}
\hline DHC scale & Male & Female & Total \\
\hline No/Little treatment need & $11(16.7 \%)$ & $55(83.3 \%)$ & 66 \\
\hline Borderline treatment need & $27(33 \%)$ & $55(67 \%)$ & 82 \\
\hline Great/Severe treatment need & $104(39.4 \%)$ & $160(60.6 \%)$ & 264 \\
\hline Total & $142(34.5 \%)$ & $270(65.5 \%)$ & 412 \\
\hline
\end{tabular}

Table 5: Frequency distribution of AC scale according to gender

\begin{tabular}{|l|c|c|c|}
\hline AC Scale & Male & Female & Total \\
\hline No/Little treatment need & $25(23 \%)$ & $84(77 \%)$ & 109 \\
\hline Borderline treatment need & $45(34.15 \%)$ & $87(65.9 \%)$ & 132 \\
\hline Great/Severe treatment need & $72(42.1 \%)$ & $99(57.9 \%)$ & 171 \\
\hline Total & $142(34.5 \%)$ & $270(65.5 \%)$ & 412 \\
\hline
\end{tabular}

Figure 4: Percentage of DHC and AC scale of IOTN

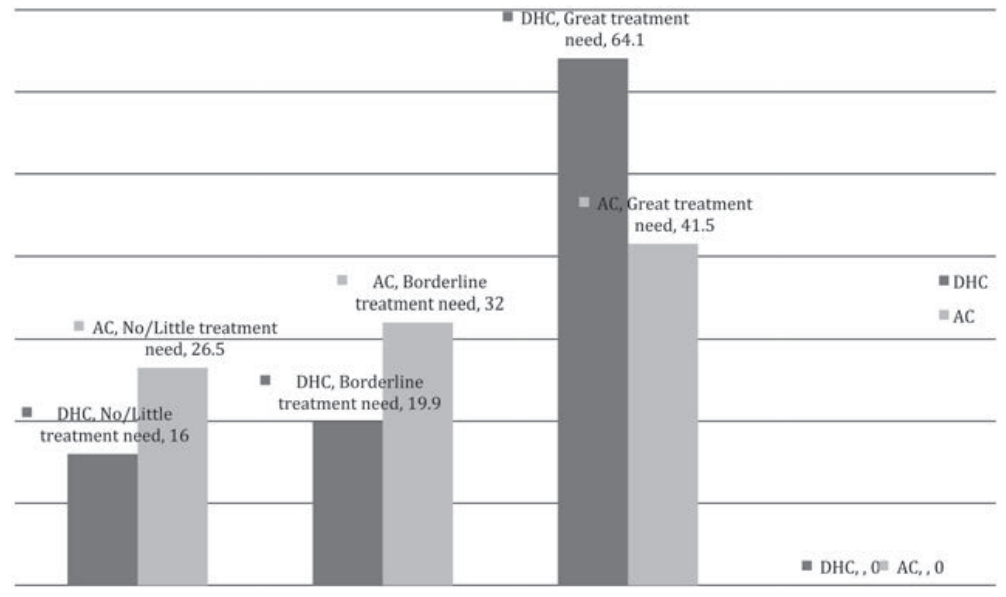

\section{DISCUSSION:}

Malocclusion being one of the major oral health problems afflicting oral functions and oral-facial aesthetics should be addressed by health authorities within the reach of the common people. Thus the researches and epidemiological studies should be conducted in the field of orthodontics of the Nepalese population to plan and to provide the service. One such study relating to the orthodontic treatment need was performed by Sharma ${ }^{20}$ on eastern Nepalese population. The Dental Health Component of IOTN of the study showed that $62 \%$ had a severe need of treatment, $28.1 \%$ had moderate 


\section{ORTHODONTIC JOURNAL OF NEPAL}

Table 6: Comparative distribution of ratings of IOTN in various referred population

\begin{tabular}{|c|c|c|c|c|}
\hline Population & \multicolumn{2}{|c|}{ DHC } & \multicolumn{2}{|c|}{$\mathrm{AC}$} \\
\hline England & No need & $5.9 \%$ & No need & $18.8 \%$ \\
\hline Brook \& Shaw (1989) & Moderate & $19.7 \%$ & Moderate & $49.3 \%$ \\
\hline$n=222$ & Great need & $74.4 \%$ & Great need & $31.4 \%$ \\
\hline Switzerland & No need & $4.1 \%$ & No need & - \\
\hline Firestone et al (1999) & Moderate & $14.3 \%$ & Moderate & - \\
\hline $\mathrm{n}=95$ & Great need & $81.6 \%$ & Great need & - \\
\hline Turkey & No need & $4.8 \%$ & No need & $45.6 \%$ \\
\hline Ucuncu \& Ertugay (2001) & Moderate & $12.0 \%$ & Moderate & $17.6 \%$ \\
\hline$n=250$ & Great need & $83.2 \%$ & Great need & $36.8 \%$ \\
\hline Iran & No need & $6.0 \%$ & No need & $15.8 \%$ \\
\hline Padisar et al (2009) & Moderate & $28.5 \%$ & Moderate & $66.6 \%$ \\
\hline$n=343$ & Great need & $65.5 \%$ & Great need & $17.6 \%$ \\
\hline Pakistan & No need & $7.0 \%$ & No need & $32.0 \%$ \\
\hline Zahid et al (2010) & Moderate & $18.0 \%$ & Moderate & $32.0 \%$ \\
\hline$n=300$ & Great need & $76.0 \%$ & Great need & $36.0 \%$ \\
\hline Nepal & No need & $16.0 \%$ & No need & $26.5 \%$ \\
\hline Shrestha \& Shrestha (2013) & Moderate & $19.9 \%$ & Moderate & $32.0 \%$ \\
\hline$n=412$ & Great need & $64.1 \%$ & Great need & $41.5 \%$ \\
\hline
\end{tabular}

need, and $9.9 \%$ little/no need. The report on eastern Nepalese referred population is similar to the present study on the central Nepalese referred population of Kathmandu mainly on great or severe treatment need of the orthodontic service.

It has been observed that, many other related IOTN studies ${ }^{1,5,12-18}$ on other referred population groups report an increasing trend of treatment need of more severe forms of orthodontic problems according to DHC score. Similar trend has been observed in the present study on referred Nepalese population. However, similar trend is not followed with Aesthetic Component in other studies. The distribution of orthodontic patients as per the treatment need based on $\mathrm{AC}$ is variable among population groups and is not consistent with the DHC scale (Table 6).

The authors found that the aesthetic component of IOTN has certain drawbacks as the 10-grade reference photographs do not represent many common malocclusion findings of the anterior dentition; including cross bite, open bite, spacing, missing tooth, pathological defects like cleft etc. Also, it has been observed that, there is no distinct demarcation among the $A C$ grade reference photographs. Similar remark has been commented by other study as well. ${ }^{21}$

The distribution of subjects in the present study shows maximum number of patients of adolescent age groups and females; the findings are obvious for the population groups which mostly seek the orthodontic treatment. The malocclusion status of the referred Nepalese population according to Angle's classification observed in the present study is consistent with the finding of the similar study on Nepalese orthodontic patients conducted in the past. The patients' malocclusion status of the present study were 54.4 \% Class I, $37.3 \%$ Class II, 8.3 \% Class III; which are in close similarity with the study conducted by Bhattarai and Shrestha, ${ }^{22}$ showing $54.5 \%$ Class I, $37.5 \%$ Class II, 8 $\%$ Class III in a sample of 200 orthodontic patients.

\section{CONCLUSION:}

According to the findings of the present study it can be concluded that $64.1 \%$ of the Nepalese referred population require great/severe treatment need according to the objective clinical findings of Dental Health Component and $41.5 \%$ require great/severe treatment need according to the subjective dental attractiveness of Aesthetic Component.

The study found the increasing trend of treatment need for more severe forms of orthodontic problems according to DHC and AC scores in age groups $11-25$ years and for both male and female gender groups.

Grade 8 of AC accounts highest percentage (18.7\%) among the subjects, i.e. ectopic canines were the utmost driving factor for the referred population. 


\section{REFERENCES}

1. Birkeland K, Boe OE, Wisth PJ. Relationship between occlusion and satisfaction with dental appearance in orthodontically treated and untreated groups. A longitudinal study. Eur J Orthod 2000; 22: 509-518.

2. Grainger RM. Orthodontic Treatment Priority Index. 1967. Public Health Service Publication No. 1000, Series 2, No. 25, US Government Printing Office, Washington DC.

3. Salzmann JA. Handicapping malocclusion assessment to establish treatment priority. Am J Orthod. 1968; 54: 749-65.

4. Summers CJ. A system for identifying and scoring occlusal disorders. Eur J Orthod. 1971;19:271-77.

5. Brook PH, Shaw WC. The development of an index of orthodontic treatment priority. Eur J Orthod 1989; 11: 309-20.

6. Richmond S, Shaw WC, O.Brien KD, Buchanan IB, Jones R, Stephens CD, Roberts CT, Andrews M. The development of PAR Index (Peer Assessment Rating): Reliability and validity. Eur J Orthod. 1992; 14: 125-139.

7. Evans R, Shaw WC. Preliminary evaluation of an illustrated scale for rating dental attractiveness. Eur J Orthod 1987; 9: 314-18.

8. Burden DJ, Holmes A. The need for Orthodontic treatment in the child population of the United Kingdom. Eur J Orthod 1994; 16: 395-399.

9. Mandall NA, McCord AS, Blinkhorn HV, Worthington KD. Perceived aesthetic impact of malocclusion and oral self-perception in 14-15 years old Asian and Caucasian children in greater Manchester. Eur J Orthod 1999; 21: 175-83.

10. Kok YV, Mageson P, Harradine NW, Sprod AJ. Comparing a quality of life measure and the Aesthetic Component of the Index of Orthodontic Treatment Need (IOTN) in assessing orthodontic treatment need and concern. J Orthod 2004; 31: 312-18.

11. Holmes A, Willmot DR. The consultant orthodontics group 1994 survey of the use of the Index of Orthodontic Need (IOTN). Br J Orthod 1996; 23(1): 57-59.

12. Richmond S. A critical evaluation of orthodontic treatment in the general dental services of England and wales. PhD thesis, University of Manchester; 1990.

13. Richmond S., Roberts CT, Andrews M. Use of Index of Orthodontic treatment Need (IOTN) in assessing the need for orthodontic treatment pre- post-appliance therapy. Br J Orthod. 1994; 21: 175-184.

14. Firestone AR, Hasler RU, Ingervall B. Treatment results in dental school orthodontic patients in 1983 and 1993. Angle Orthod 1999; 69:19-26.

15. Uncuncu N, Ertugay E. The use of Index of Orthodontic Treatment Need (IOTN) in a school population and a referred population. J Orthod 2001; 28(1): 45-52.

16. Hedayati Z, Fattahi HR, Jahromi SB. The use of index of orthodontic treatment need in an Iranian population. J. Ind. Soc. Pedod Prev. Dent. 2007; 25: 10-14.

17. Padisar P, Mohammadi Z, Nesseh R, Marami A. The use of Orthodontic Treatment Need Index (IOTN) in a referred Iranian population. Research J Biological Sciences. 2009; 4(4):438-43.

18. Zahid S, Bashir U, Arshad N, Kaleem OH, Hasan R, Iftikhar A, Shah AH. Orthodontic treatment need in 13-30 years patients by using the Index of Orthodontic Treatment Need. Pakistan Oral \& Dent J. 2010; 30(1): 108-14.

19. Lunn H, Richmond S, Mitropoutous C. The use of the Index of Orthodontic Treatment Need (IOTN) as a public health tool: A pilot study. Community Dent Health. 1993; 10: 111-121.

20. Sharma JN. Epidemiology of malocclusion and assessment of orthodontic treatment need for the population of eastern Nepal. World J Orthod. 2009 winter; 10(4):311-6

21. Johansson AM, Folin ME. Evaluation of the aesthetic component of the Index of Orthodontic treatment Need by Swedish orthodontists. Euro J Orthod. 2005; 27: 160-66.

22. Bhattarai P, Shrestha RM. Prevalence of malocclusion among Nepalese Orthodontic patients according to Angle's Classification. 2008; J Nep Dent Asso, 9:1: 29-35. 